ORIGINAL ARTICLE

\title{
Vitamin D Levels in Patients Presenting with Non-Specific Neuromuscular Pain and Fatigue in Ethiopia
}

\author{
Guta Zenebe $^{1^{*}}$
}

\section{OPEN ACCESS}

Citation: Guta Zenebe. Vitamin D levels in Patients Presenting with Non-Specific Neuromuscular Pain and Fatigue in Ethiopia: A Retrospective Review. Ethiop J Health Sci. 2020;30(3):337. doi:http://dx.doi.org/10.4314/ejhs.v30 i3.4 Received: January 10, 2020 Accepted: January 29, 2020 Published: May 1, 2020

Copyright: (C2020 Guta Zenebe, et al. This is an open access article distributed under the terms of the Creative Commons Attribution License, which permits unrestricted use, distribution, and reproduction in any medium, provided the original author and source are credited. Funding: Nil

Competing Interests: The authors declare that this manuscript was approved by all authors in its form and that no competing interest exists.

Affiliation and Correspondence:

${ }^{1}$ Department of Neurology, School of

Medicine College of Health Sciences

Addis Ababa University

*Email: gutazenebe@icloud.com

\begin{abstract}
BACKGROUND: Vitamin $D$ is an important micronutrient impacting multiple physiologic functions including calcium, phosphorus and bone metabolism. Various studies demonstrate low vitamin $D$ levels in non-specific neuromuscular pain disorders and chronic-fatigue-syndromes. This observation was supported by significant improvement of these disorders following Vitamin $D$ supplementation. Several studies demonstrate low serum vitamin D levels in healthy adult Ethiopians despite availability of abundant sunlight.
\end{abstract}

METHOD: Retrospective medical records review of 62 patients presented to Yehuleshet Specialty Clinic between March 2014August 2015 with non-specific neuromuscular pain and fatigue. Serum vitamin D levels were obtained at initial clinic visit.

RESULTS: The mean $( \pm S D)$ age was $51.5 \pm 15.5$ years. Two-third (69.4\%) of the participants were female. The majority (56.5\%) presented with mixed symptoms, including generalized body ache, paresthesia, neck and back pain, while $45.2 \%$ reported fatigue. Fifteen (24.2\%) participants were on antiepileptic drugs. All patients had initial serum vitamin D levels $<30 \mathrm{ng} / \mathrm{ml}$, among these $62.9 \%$ demonstrated severe deficiency $(<12 \mathrm{ng} / \mathrm{ml})$. Thirty (48.4\%) participants reported symptomatic improvement after treatment with standard doses of vitamin $D$ and calcium. Age $>50$ years, being housewife, use of antiepileptic medications (AEDs), and higher serum parathyroid hormone are associated with severe vitamin $D$ deficiency.

CONCLUSION: This study demonstrated high prevalence of vitamin $D$ deficiency among patients with non-specific neuromuscular pain and fatigue. Vitamin D replacement resulted in significant clinical improvement. It is important to screen vitamin $D$ in individuals with limited sunlight exposure and patients on AEDs when presenting with neuromuscular pain and fatigue.

KEYWORDS: Neuromuscular pain, fatigue, vitamin D deficiency 


\section{INTRODUCTION}

Vitamin D is a fat-soluble vitamin that promotes calcium and phosphorus absorption in the gut, thereby maintaining normal serum calcium and phosphate concentrations and enabling normal bone mineralization, bone growth, and remodeling. In addition to its role in calcium and bone homeostasis, vitamin D potentially regulates many other cellular functions. The vitamin D receptor (VDR) is nearly universally expressed in nucleated cells (1). Humans receive $80-90 \%$ of their vitamin D supply through ultraviolet B sunlight exposure of the skin and the rest through vitamin D-containing foods (2). There are two forms of vitamin $\mathrm{D}$ : vitamin $\mathrm{D}_{2}$ or ergocalciferol (produced by plants) and vitamin $\mathrm{D}_{3}$ or cholecalciferol (produced by sunlight conversion of 7dehydrocholesterol in the skin) (3).

Vitamin D deficiency may be attributed to inadequate sun exposure, dietary insufficiency, gastrectomy and gastric bypass surgery, pancreatic disease, liver disease, renal disease, and myriad causes of malabsorption including celiac disease, lactase deficiency, Crohn's disease, parasitic infections and bacterial overgrowth. In addition, neurologic disorders are the leading cause of long term disability globally (4). These disorders include epilepsy, neuropathy, neoplastic diseases and neuroinfection necessitating the use of antiepileptic drugs (phenytoin, carbamazepine), antineoplastic and antiretroviral medications (cyclophosphamide and ritonavir, respectively), and antibiotics and anti-inflammatory agents (rifampicin, dexamethasone, respectively), all of which activate the pregnane- $X$ receptor, upregulating the 24-hydroxylases, leading to increased degradation of vitamin D. Indeed, anticonvulsant induced osteomalacia and related disorders are too common to be ignored. Vitamin D affects muscles strength, muscle bulk and neuromuscular performance (5).

There have been increasing reports over the past decade implicating vitamin $\mathrm{D}$ in sarcopenia, a reduction in skeletal muscle mass and strength. Several trials point out that there is an association between the blood serum level of $25(\mathrm{OH}) \mathrm{D}$ and musculoskeletal pain as well as non-specific back pain $(6,7)$. Vitamin D has an anti-inflammatory effect through regulation of interleukin, tumor necrosis factor, and the activity of macrophages (8), and reduces pain in diabetic polyneuropathy patients (9). Thus, the supplementation of vitamin D might theoretically have a beneficial effect on inflammatory induced pain. The aim of this study is to determine the prevalence of hypovitaminosis D among patients who presented with non-specific pain and fatigue, because vitamin D deficiency is a common and easily treatable disease.

\section{MATERIALS AND METHODS}

This is a retrospective chart review of patients who initially presented with non-specific neuromuscular pain and fatigue to Yehuleshet Specialty Clinic, located in Addis Ababa, Ethiopia. All the 62 patients presented to the clinic with the main complaints of: localized body pain (other than back and neck pain), generalized body ache, lower back pain, generalized fatigue or tiredness, neck pain, joint pain, shoulder pain and paresthesia. Serum vitamin D levels were determined and included in the review. Structured questionnaires were used to collect socio-demographic, clinical and laboratory data.

All patients were fully evaluated upon initial presentation and laboratory test included serum vitamin D levels. All the 62 patients were treated with standard treatment regimen of vitamin D deficiency: vitamin $\mathrm{D}_{3} \quad 50,000$ IU orally once weekly for four weeks + Calcium $1200 \mathrm{mg}$ orally daily, then maintenance vitamin $\mathrm{D}_{3} 1000$ IU daily orally for three months (8) and appointed for a three months-followup. Upon the second visit after three months, serum vitamin $\mathrm{D}$ was determined to look for any biochemical improvement and patients was evaluated for clinical improvement, and diagnosed as improved, no change, or lost to followup.

Seasons in Ethiopia are categorized in to four: 1) Kiremt (summer) which includes June, July and August, and often characterized by heavy rain falls in these three months; 2) Belg (autumn) which includes September, October and November- It is also harvest season-; 3) Bega (winter) which includes December, January and February-It is also dry season-; 4) Tseday (spring) includes March, April and May. Autumn season is characterized with occasional showers. May is the hottest month in Ethiopia (17).

DOI: http://dx.doi.org/10.4314/ejhs.v30i3.4 
The following references standards were used during analysis: Serum Vitamin D: Severe deficiency $(<12 \mathrm{ng} / \mathrm{ml})$, moderate deficiency (12$20 \mathrm{ng} / \mathrm{ml}$ ), mild deficiency $(20-30 \mathrm{ng} / \mathrm{ml})$, and normal $(>30 \mathrm{ng} / \mathrm{ml})$. Serum calcium: normal reference range $(2.12-2.55 \mathrm{mmol} / \mathrm{L})$, ionized calcium: normal reference range (1.16$1.32 \mathrm{mmol} / \mathrm{L}$ ), serum parathyroid hormone: normal reference range $(10-65 \mathrm{ng} / \mathrm{L})$, serum phosphorus: normal reference range $(2.5-4.5 \mathrm{mg} / \mathrm{dl})(18)$. The statistical analysis was performed using SPSS version 25.0 computer program. Descriptive analysis was done by using frequency and cross tabulation.

\section{RESULTS}

The mean $( \pm \mathrm{SD})$ age was $51.5 \pm 15.5$ years. Half of the study participants were aged above 50 years; only $4.8 \%$ of the patients were aged $\leq 29$ years. Two-third $(69.4 \%)$ of the participants were female. In the majority of the cases (58.1\%), serum vitamin $\mathrm{D}$ was determined during spring: between March to May (Table 1). Thirty-six (58.1\%) of the patients were from Addis Ababa, $11.3 \%$ were from Oromiya regional state, while one patient was from Israel, the second was from Saudi Arabia. Twenty $(32.3 \%)$ of the patients were housewives, $14.5 \%$ owned private business, and $9.7 \%$ were government employees (Table 1).

Table 1: Distribution of demographic and clinical characteristics, Yehuleshet Specialty Clinic, 2014-2015.

\begin{tabular}{|c|c|c|c|}
\hline & & Frequency & Percent (\%) \\
\hline & Mean \pm SD & $51.5 \pm 15.5$ & \\
\hline \multirow{3}{*}{ Age } & $\leq 29$ years & 3 & 4.8 \\
\hline & $30-49$ years & 28 & 45.2 \\
\hline & $\geq 50$ years & 31 & 50.0 \\
\hline \multirow[t]{2}{*}{ Gender } & Male & 19 & 30.6 \\
\hline & Female & 43 & 69.4 \\
\hline \multirow[t]{4}{*}{ Evaluation season } & Summer & 12 & 19.4 \\
\hline & Autumn & 1 & 1.6 \\
\hline & Winter & 13 & 21.0 \\
\hline & Spring & 36 & 58.1 \\
\hline \multirow[t]{7}{*}{ Regional states } & Oromiya & 7 & 11.3 \\
\hline & Amahara & 5 & 8.1 \\
\hline & Ethiopian Somali & 1 & 1.6 \\
\hline & SNNP & 5 & 8.1 \\
\hline & Outside Ethiopia & 2 & 3.2 \\
\hline & Addis Ababa & 36 & 58.1 \\
\hline & Others & 3 & 4.8 \\
\hline \multirow[t]{4}{*}{ Occupation } & Private business & 9 & 14.5 \\
\hline & Government Employee & 6 & 9.7 \\
\hline & Housewife & 20 & 32.3 \\
\hline & Pension & 4 & 6.5 \\
\hline \multirow[t]{7}{*}{ Presenting symptoms } & Generalized body ache & 4 & 6.5 \\
\hline & Localized body aches & 4 & 6.5 \\
\hline & Lower back pain & 13 & 21.0 \\
\hline & Neck pain & 4 & 6.5 \\
\hline & Joint pain & 1 & 1.6 \\
\hline & Mixed symptoms & 35 & 56.5 \\
\hline & Tremor & 1 & 1.6 \\
\hline \multirow[t]{2}{*}{ Fatigue } & Yes & 28 & 45.2 \\
\hline & No & 34 & 54.8 \\
\hline
\end{tabular}

DOI: http://dx.doi.org/10.4314/ejhs.v30i3.4 
In cross tabulation, analysis done between different degree of hypovitaminosis D and age category; moderate and severe vitamin D deficiency was observed in those individual aged 50 years and above. Housewives tended to have more severe vitamin $\mathrm{D}$ deficiency. That is, their serum vitamin D was found to be $<20 \mathrm{ng} / \mathrm{ml}$.

The most common presenting complaints were mixed symptoms (56.5\%), including: generalized body ache, neck pain, back pain and paresthesia. Twenty-eight (45.2\%) individuals reported fatigue in addition to non-specific pain. Lower back pain and neck pain were reported in $21 \%$ and $6.5 \%$, respectively (Table 1).Twenty-two $(35.5 \%)$ of the patients reported additional symptoms, other than the presenting symptoms (Figure 1). Headache and pain were the commonest additional symptoms patients reported. Excessive sweat, dizziness and gait abnormalities were additional symptoms that were reported (Figure 1). Seventeen $(27.4 \%)$ of the patients had diagnosis of radiculopathy, while Osteoporosis, Osteoarthritis, and peripheral neuropathy accounted for $12.9 \%, 12.9 \%$ and $11.3 \%$, respectively. Parkinson's disease accounted for $8.1 \%$, thyroid disorders accounted for $3.2 \%$ and Neurosyphilis accounted for $3.2 \%$ (Table 2).

Table 2: Frequency distribution of patient diagnoses, Yehuleshet Specialty Clinic, 2014-2015.

\begin{tabular}{|c|c|c|c|}
\hline & & Frequency & Percent (\%) \\
\hline \multirow[t]{14}{*}{ Diagnosis } & Osteoporosis & 8 & 12.9 \\
\hline & Osteoarthritis & 8 & 12.9 \\
\hline & Rheumatoid arthritis & 2 & 3.2 \\
\hline & Radiculopathy & 17 & 27.4 \\
\hline & Hypocalcaemia & 3 & 4.8 \\
\hline & Ataxia & 1 & 1.6 \\
\hline & Peripheral neuropathy & 7 & 11.3 \\
\hline & Myopathy & 1 & 1.6 \\
\hline & Trigeminal Neuralgia & 1 & 1.6 \\
\hline & Thyroid disorders & 2 & 3.2 \\
\hline & Parkinson's disease & 5 & 8.1 \\
\hline & Seizure disorders & 2 & 3.2 \\
\hline & NMS pain syndrome & 3 & 4.8 \\
\hline & Neurosyphilis & 2 & 3.2 \\
\hline \multirow[t]{6}{*}{ AED used } & Phenytoin & 2 & 3.2 \\
\hline & Carbamazepine & 5 & 8.1 \\
\hline & Valproate & 3 & 4.8 \\
\hline & Phenobarbitone & 2 & 3.2 \\
\hline & Combination anticonvulsant & 2 & 3.2 \\
\hline & Others & 1 & 1.6 \\
\hline
\end{tabular}

ๆ NMS: Nonspecific musculoskeletal; ๆ AED: Antiepileptic drugs 


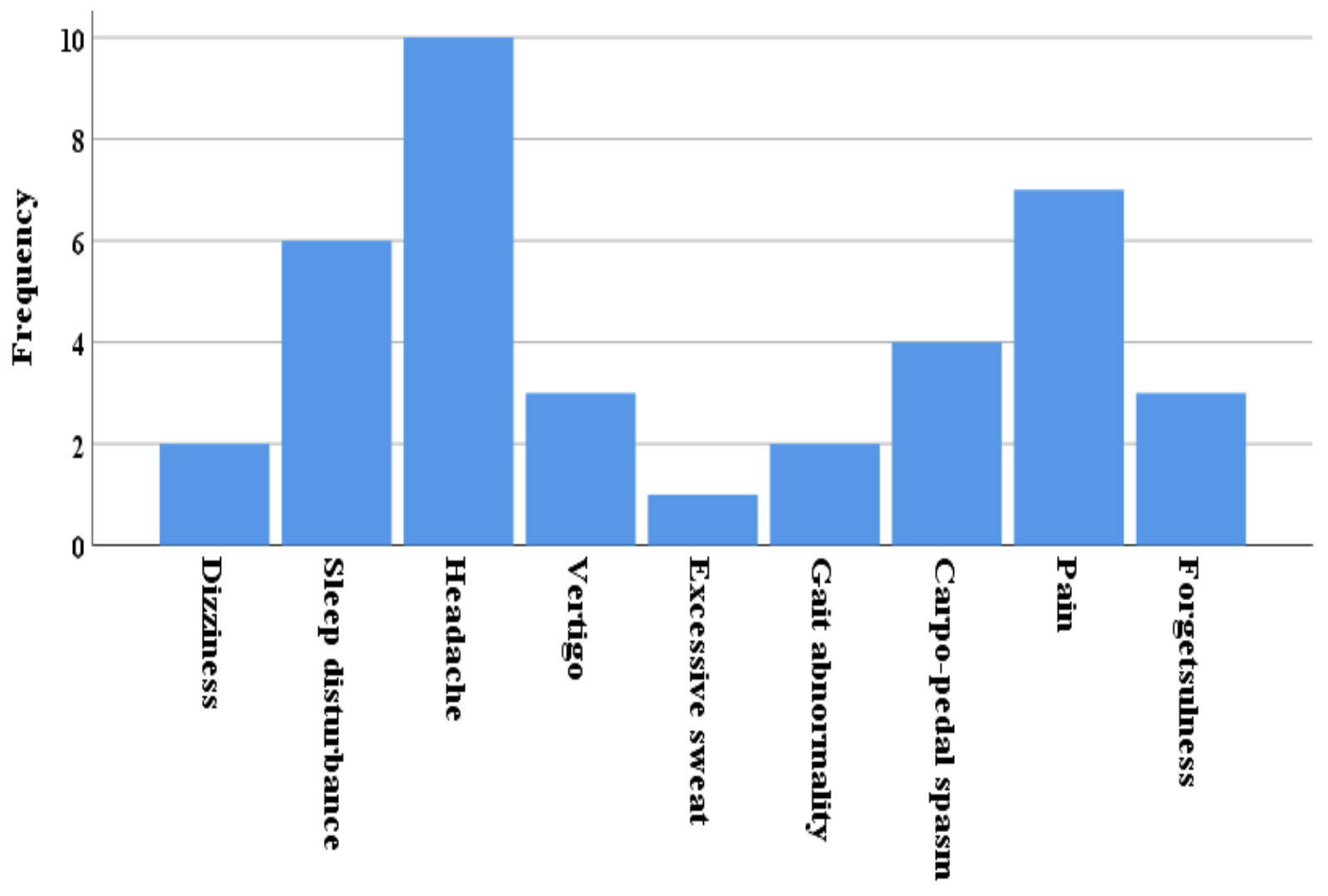

Figure 1: Bar graph showing distribution of additional symptoms patients reported

Hypertension is the commonest comorbid disorder identified in our study participants, followed by Diabetes mellitus. Out of 62 patients, 2 were HIV+ patients on ART, presented with non-specific pain and fatigue (Figure 2). Out of 62 patients, fifteen $(24.2 \%)$ were on different types of antiepileptic medications. The majority $(8.1 \%)$ of them were on carbamazepine, $4.8 \%$ were on valproate, while
$3.2 \%$ of the patients were on phenytoin (Table 2). Those patients who were on antiepileptic medications tended to have more moderate to severe vitamin D deficiency, than mild deficiency states. Out of total 15 patients on antiepileptic medications, $12(80 \%)$ had moderate to severe vitamin $\mathrm{D}$ deficiency, while 2 had adequate serum vitamin D. 


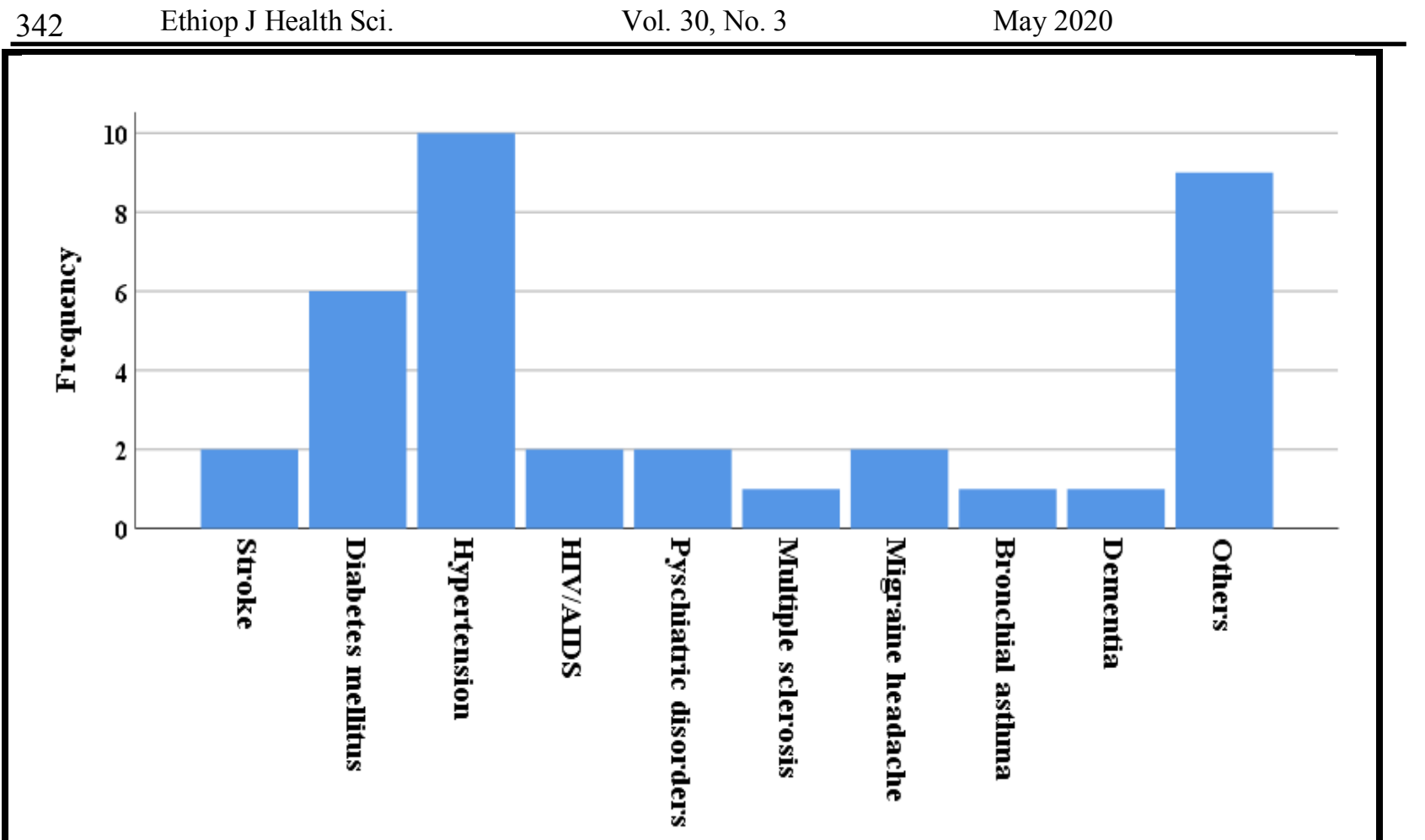

Figure 2: Bar graph showing frequency distribution of comorbid disorders

All of our study participants had initial serum vitamin $\mathrm{D}$ determined upon presentation. Out of 62 patients, the majority $(62.9 \%)$ had severe hypovitaminosis $\mathrm{D}(<12 \mathrm{ng} / \mathrm{ml})$. only 2 patients had mild deficiency (Table 3). Twenty-three (37\%) of the patients had followup serum vitamin D determined. The majority of them attained adequate serum vitamin D level, while still $8.1 \%$ had moderate deficiency. Out of 48 individuals whose total calcium was determined $67.7 \%$ had normal total calcium level. Out of 14 patients whose serum parathyroid level was determined, $16.1 \%$ had elevated parathyroid hormone level. Of these, two-third of the patients whose parathyroid hormone level was found to be high had moderate to severe vitamin deficiency (Table 3). Out 62 patients, 17 had serum phosphorus determined; among these, $22.6 \%$ had normal serum level (Table $3)$.

Out of 62 patients, 11 were screened for HIV serology, and two of them were found to be positive. A total of $61.3 \%$ were screened for syphilis by using VDRL test, and 2 were positive. Hepatitis B virus, Hepatitis C virus and Antinuclear antibody screening was done, and positive results were seen in $3.2 \%, 1.6 \%$ and $1.6 \%$, respectively. Out of 62 patients, half reported clinical improvement on their presenting symptoms (Figure $3)$. 
Table 3: Frequency of serum level of Vitamin D, Calcium, PTH and Phosphorus, Yehuleshet Specialty Clinic, 2014-2015

\begin{tabular}{llcc}
\hline \multirow{3}{*}{ Initial Vitamin D } & & Frequency & Percent (\%) \\
\cline { 2 - 3 } Follow up Vitamin D & Mild deficiency & 2 & 3.2 \\
& Moderate deficiency & 21 & 33.9 \\
& Severe deficiency & 39 & 62.9 \\
& Adequate level & 15 & 24.2 \\
& Mild deficiency & 3 & 4.8 \\
& Moderate deficiency & 5 & 8.1 \\
Total serum calcium & Normal & & \\
& Low & 42 & 67.7 \\
& Not determined & 6 & 9.7 \\
Ionized calcium & Normal & 14 & 22.6 \\
& Low & 31 & 50.0 \\
& Not determined & 2 & 3.2 \\
Parathyroid hormone & Normal & 29 & 46.6 \\
& High & & 6.5 \\
& Not determined & 4 & 16.1 \\
Phosphorus & & 10 & 77.4 \\
& Normal & 48 & 22.6 \\
& Low & & 4.8 \\
& Not determined & 14 & 72.6 \\
\hline
\end{tabular}

I PTH: Parathyroid hormone

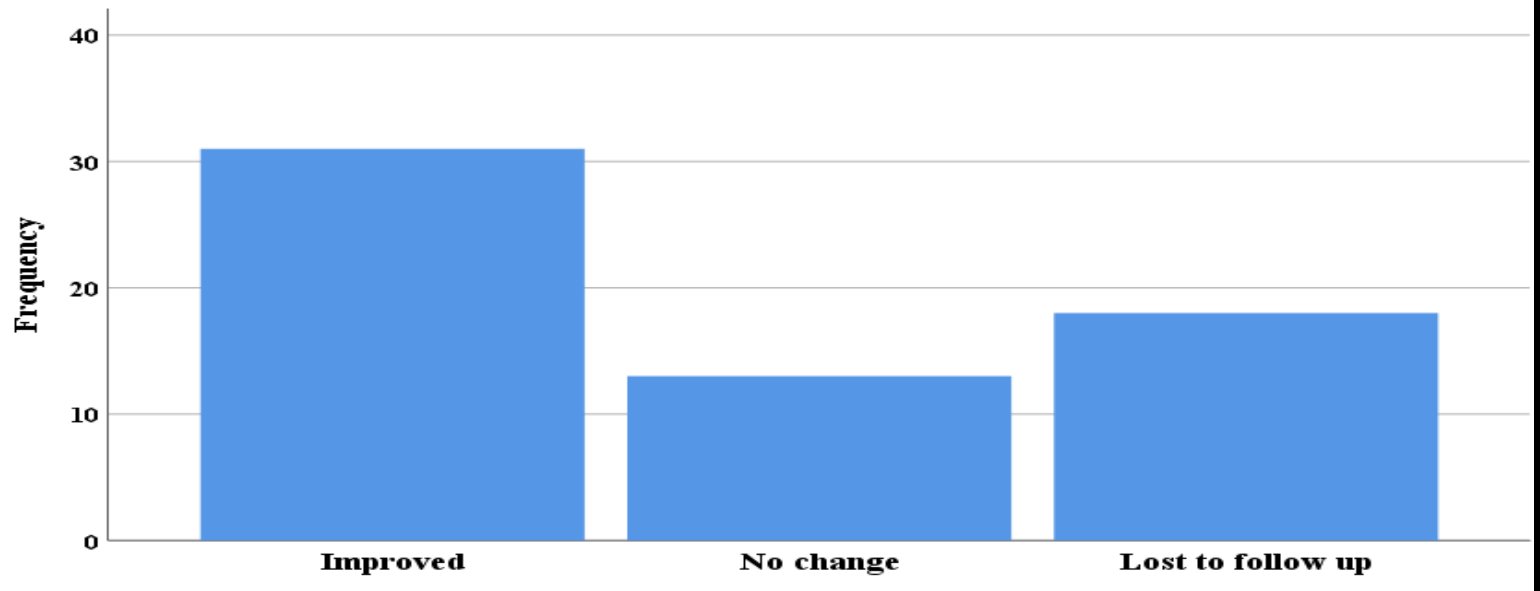

Figure 3: Bar graph showing clinical outcome after three months treatment with vitamin D 


\section{DISCUSSION}

All of our study participants (100\%) had vitamin D deficiency, in which more than half of them had severe hypovitaminosis D $(<12 \mathrm{ng} / \mathrm{ml})$. Those individuals above the age of 50 years, housewives and those on antiepileptic medications tended to have a more severe vitamin D deficiency. More than half of our patients presented with mixed symptoms, including: generalized body ache, neck pain and back pain and paresthesia, while twentyeight $(45.2 \%)$, reported fatigue on top of the nonspecific pain. This finding comports with a Swiss report in which all of the participants initially presented with musculoskeletal pain, pain localized in shoulders, ribs, lower back and thighs, and fatigue (10). A Minnesota study demonstrated that $28 \%$ of patients presenting with persistent nonspecific musculoskeletal pain to a community health centre had severe hypovitaminosis $\mathrm{D}$, which further emphasize the importance of this disorder (11).

Knutsen et al (5) reported possible association between vitamin $\mathrm{D}$ deficiency and presences of headache disorders. These findings were consistent to findings from this review, in which most of the patients reported headache (Figure 1). These findings may lead to further studies addressing the possible association between headache disorders and $\mathrm{D}$ deficiency. This is particularly important, because migraine headache is associated with severe disability among Ethiopians (12). Radiculopathy, osteoporosis, and osteoarthritis were the top three most common-diagnoses among the study participants. Our study indicated that hypovitaminosis $\mathrm{D}$ is prevalent among patients with comorbid disorders, such as hypertension and diabetes mellitus (13). One-fourth of our patients were on antiepileptic medication which is one of the risk factors for development of hypovitaminosis D (14). Feleke et al (15) reported that greater proportion of people in Ethiopia had vitamin D deficiency despite abundant sun availability. The authors also explained low vitamin D among Ethiopians, likely related to the dressing habit, as most people, especially women tend to cover most of their body parts. These findings were supported by our study findings, where females are the majority and they tend to have more severe hypovitaminosis $\mathrm{D}$, which could be explained by the fact that they are mostly housewives and spend a significant amount of their time indoor. Vitamin D insufficiency appears to be common among several other populations, including: dark skinned, obese, hospitalized, institutionalized, and individuals who consistently use sun screens and wear protective clothes. These is because, high melanin level inhibits the production of vitamin D in the skin. Sunscreen prevents sunburn by blocking UVB light. Therefore, sunscreen use lowers vitamin D levels. However, as a practical matter, very few people put on enough sunscreen to block all UVB light, or they use sunscreen irregularly, so sunscreen's effects on vitamin D might not be significant in our setup $(15,19)$.

Serum total calcium was observed to be fairly well maintained in most of our patients, despite observed high prevalence of vitamin D deficiency. This observation may need further community based study to understand the community level of serum vitamin D and calcium among Ethiopians, as dietary habit could potentially affect this finding. In this review, elevated serum parathyroid hormone level was observed indicating, hypovitaminosis D maybe one cause of hyperparathyroidism. Those individuals who were aged above 50 years, patients on antiepileptic medications, housewives, and those having elevated serum parathyroid hormone were found to have more severe hypovitaminosis D. These indicate the need to screen those individuals at risk of developing vitamin D deficiency.

Vitamin D and its activated form 1.25dihydroxyvitamin $\mathrm{D}$ have a complex role in immunological system; 1.25-dihydroxyvitamin D has an important modulator effect on $T$ lymphocytes. One of the most important observations from this review is the fact that half of the patients showed clinical symptom improvement after standard dose vitamin D and calcium replacement at three months followup period. These findings are consistent with the finding by Malabanan et al. (16), in which patients with nonspecific chronic pain, muscle pain, fall and weakness reported decreases in $25 \%$ after vitamin D replacement. Sufficient sun exposure can

DOI: http://dx.doi.org/10.4314/ejhs.v30i3.4 
provide an adequate amount of vitamin $\mathrm{D}_{3}$, which is stored in body fat and released during the winter, when vitamin $\mathrm{D}_{3}$ cannot be produced (8). Exposure of arms and legs for 5 to 30 minutes between the hours of 10 a.m. and 3 p.m. twice a week is often adequate (8). In addition, diet should contain sufficient amounts of vitamin D. After patients attain sufficient vitamin D serum level, they have to continue having adequate sun exposure and take diet that contains sufficient amount of vitamin D and calcium and vitamin D supplementation. According to recommendations from the Institute of Medicine, adequate daily intake of vitamin D is 200 IU daily for children and adults up to age 50 years. For adults' age between 51 to 70 years of age, $400 \mathrm{IU}$ daily, and $600 \mathrm{IU}$ daily for adults age above 71 years. However, most experts agree that without adequate sun exposure, children and adults require approximately 800 to $1000 \mathrm{IU}$ per day (8). Limitations of this study are, being retrospective review, absence of controlled group for comparison, and relatively high loss to followup cases. The latter may be explained by the fact that, some of the patients are from the regional cities and outside Ethiopia; therefore they failed to show up at third month followup.

These results support screening of all patients presenting with non-specific neuromuscular pain, back pain, paresthesia and fatigue for hypovitaminosis D in Ethiopia, despite abundant sunshine throughout the year. These paradoxical findings are most likely attributable to inadequate sun exposure practice and change in life style where most people spend their working and living time under shades. In addition, their diet contains insufficient amounts of vitamin D3. This is the first study to be reported from Ethiopia, assessing the prevalence of vitamin D deficiency among patients who presented with non-specific neuromuscular pain and fatigue. It is vital to conduct large scale community based studies to ascertain the baseline serum vitamin $\mathrm{D}$ and calcium level among different Ethiopian populations, to further understand the exact causes of vitamin D deficiency, uncover additional manifestations of vitamin D deficiency, and identify other comorbid disorders which could predispose individuals to vitamin $\mathrm{D}$ deficiency.

\section{ACKNOWLEDGEMENT}

I would like to extend my heartfelt gratitude to Dr. Mehila Zebenigus and Dr. Biniyam Alemayehu for their unlimited cooperation during data collection process.

\section{REFERENCES}

1. Bouillon R. Vitamin D: from photosynthesis, metabolism and action to clinical applications in Endocrinology, 2010:1:1089. Elsevier, Philadelphia.

2. Norman AW. From vitamin D to hormone D: Fundamentals of the vitamin D endocrine system essential for good health. Am J Clin Nutr, 2008(88)49:1S - 9S.

3. Donnino MW, Miller J, Garcia AJ, Distinctive acid-base pattern in Wernicke's encephalopathy. Ann Emerg Med, 2007: 50:722.

4. Global Burden of Disease (GBD). A systematic analysis for the Global Burden of Disease Study, Lancet Neurol, 2016:18: 43958.

5. Knutsen, KV, Brekke M. Gjelstad S, Lagerlov P. Vitamin D status in patients with musculoskeletal pain, fatigue and headache: A cross-sectional descriptive study in a multiethnic general practice in Norway. Scand. J. Prim. Health, 2010:28:166-171.

6. Holick MF. Vitamin D: A delightful solution for health. J. Invest. Med. 2011:59:872-880.

7. Reuss-Borst. Metabolic bone disease osteomalacia. Z. Rheumatol. 2014:73: 316322.

8. Holick MF. Vitamin D deficiency. $N$ Engl $J$ Med, 2007:357:266 - 81.

9. Lee P, Chen R. Vitamin D as an analgesic for patients with type 2 diabetes and neuropathic pain. Arch Intern Med, 2008:168:771 - 2 .

10. De Torrente DL, Jara G., Pecoud A, Favrat B., Musculoskeletal pain in female asylum seekers and hypovitaminosis D3. BMJ, 2004: 329 (7458) 156-157.

11. Plotnikoff GA, Quigley JM. Prevalence of severe hypovitaminosis $\mathrm{D}$ in patients with

DOI: http://dx.doi.org/10.4314/ejhs.v30i3.4 
persistent, nonspecific musculoskeletal pain. Mayo Clin Proc, 2003: 78:1463-70.

12. Ayele and Yifru, Migraine-related disability and co-morbid depression among migraineurs in Ethiopia: a cross-sectional study, $B M C$ Neurology, 2018: 18:95, https://doi.org/10.1186/s12883-018-1095-3.

13. Bell DH. Reversal of the symptoms of diabetic neuropathy through correction of vitamin D deficiency in a type 1 diabetic patient. Case Rep Endocrinol. 2012:16:50-56 https://doi.org/10.1155/2012/165056.

14. Lavie CJ, Lee JH, Milani RV. Vitamin D and Cardiovascular Disease Will It Live Up to its Hype? Journal of the American College of Cardiology, 2011: 58:1547-56.

15. Feleke Y, Abdulkader J, Mshana R, Mekbib T, Brunvand L, Berg JP, Falch JA. Low levels of serum Calcidiol in an African population compared to a north European population, European Journal of Endocrinology. 1999:141:358-360.

16. Holick MF. Vitamin D: important for prevention of osteoporosis, cardiovascular heart disease, type 1 diabetes, autoimmune diseases, and some cancers. South Med J 2005: 98:10247.

17. Ethiopian Seasonal distribution, Ethiopian Treasures, July, 2019.

18. Standard reference ranges, ABIM Laboratory Test Reference Ranges, January 2019.

19. Looker AC, Pfeiffer CM, Lacher DA. Serum 25-hydroxyvitamin $\mathrm{D}$ status of the US population: 1988-1994 compared with 20002004. Am J Clin Nutr 2008:88:1519. 